\title{
Graduates' Satisfaction of Education and Teaching Job Based on Logistics Management in Application Colleges and Universities
}

\author{
Shufan Zhu ${ }^{1, a^{*}}$ and Rongyan Zhu ${ }^{2, b}$ \\ ${ }^{1}$ Lecturer, Senior Logistics Division, School of Logistics Management, Wuhan Technology and \\ Business University, No.3, Huangjiahu west road, Wuhan, Hubei, China \\ ${ }^{2}$ Ph.D, Hubei Business Service Development Research Center, Wuhan Technology and Business \\ University, No.3, Huangjiahu west road, Wuhan, Hubei, China \\ azhu_shufan1@163.com, 'bhurongyan1985@163.com \\ * The Corresponding Author
}

Keywords: Applied universities; Education and teaching job satisfaction; Statistical analysis; Regression analysis

\begin{abstract}
This paper presents graduates' satisfaction of education and teaching job in applied colleges and Universities. Based on related theory, this paper collects information by the questionnaire survey form and analyzes statistics result of the questionnaire and interview, finding out the influence factors and reasons of graduates' education and teaching satisfaction. Therefore, this paper summarizes some possible problems in the education and teaching and provides basis and countermeasures to improve education teaching effectiveness and satisfaction. Based on above analysis this paper can help build a communication bridge between students and enterprises, which make the students more smooth, more quickly integrate into the enterprise, even social atmosphere.
\end{abstract}

\section{Introduction}

As an important part of education system in China, students' education problems affect the whole society's nerves in applied colleges and universities. Compared with other schools, applied colleges and universities pay more attention to the improvement of students' professional skills, so as to cultivate the practical talents needed by the society. At present, college graduates have some misunderstanding in employment concept, for example, some students with bad attitude, job return expectations too high, the lack of information, excessive dependence and blind confidence, some for entrepreneurship blindly following, which put forward new challenges for students' employment education. Therefore, it is very important to carry out effective education and guidance for graduates. How to more effectively develop education and teaching work in applied colleges and universities, and provide valuable information and correct guidance for students have become an important subject worth thinking about.

\section{Data Sources and Research Methods}

Data Sources. Study samples are derived from logistics professional graduates of several applied colleges in Hubei province. Before designing questionnaire survey, the author had interviewed logistics professional education experts deeply at first, and had finished a lot of research on related literature. To better reflect education and teaching job satisfaction of logistics management graduates, the questionnaire distributed objects respectively are logistics professional graduates in three applied colleges. The questionnaire is issued on site, all taking anonymous questionnaire way to fill in. the questionnaire is constituted of nearly 123 questionnaires and ultimate recover of 115 , eliminating invalid four questionnaires, 111 valid questionnaires, of which effective recovery rate reach $90.24 \%$, in line with the requirements of the social survey. This questionnaire adopts the five-level scoring method, which is very satisfied with 5 points, 4 points for satisfaction, 3 points for the general satisfaction, 2 points for unsatisfactory, and 1 point for very unsatisfactory. 
Research Methods. The questionnaire is composed of five variables, including professional ethics, professional knowledge, practical ability, comprehensive quality training, management and service. The first variable "professional moral quality" includes three questions of guiding ideology and importance. The second variable "professional knowledge ability" includes 8 items of professional setting, curriculum setting and teaching staff. The third variable "practical ability" includes three items: practical teaching arrangement and vocational skill training. The fourth variable "comprehensive quality training" includes 4 items of mental health education and sports work. The fifth variables "management and service" includes 6 item of college library service quality, canteen service quality, students' dormitory service quality and students' work-study job, the last item "overall satisfaction of school education and teaching work" is overall satisfaction for students. questionnaire is constituted of 24 items, which are analyzed with SPSS16 statistical analysis software after recycling. independent variable and dependent variable are named from A1 to $\mathrm{F}$ factor, then respectively for reliability and validity analysis, variance analysis, descriptive analysis, correlation analysis and regression analysis.

\section{Influence Factors on Graduates' Satisfaction of Education and Teaching Job in Applied Colleges and Universities}

Reliability and Validity Analysis. When data is processed, reliability and validity of questionnaire should be analyzed to ensure the consistency and validity of survey data.

(1)reliability analysis

Table 1 Reliability coefficient of education and teaching job satisfaction questionnaire for graduates

\begin{tabular}{|c|c|c|}
\hline Cronbach's Alpha & $\begin{array}{c}\text { Cronbach's Alpha Based on } \\
\text { Standardized Items }\end{array}$ & N of Items \\
\hline .881 & .895 & 6 \\
\hline
\end{tabular}

Reliability is an important index to measure the consistency of questionnaire, indicating the reliability of measurement. Cronbach's alpha coefficient is one of the most commonly used methods in reliability measurement. value is greater than 0.7 , showing that the data is reliable. You can see from table 1, the five variables Cronbach's alpha is above 0.7 , and the value of total table is 0.881 . Therefore, the questionnaire can be thought to have high consistency and the survey data is reliable.

(2) validity analysis

Validity is an important index to measure the validity of questionnaire, and indicates the consistency degree of multiple measurement results. The higher the validity, the more the test results show the correct degree of measure object. Conversely, if the validity is not high, the effectiveness of the measuring tool can not be truly realized. It is generally believed that KMO value is distributed between 0.7-0.8 and Bartlett's sphere test results are significant, indicating that the questionnaire has a good overall validity.

Table 2 Validity coefficient of education and teaching job satisfaction questionnaire for graduates

\begin{tabular}{|c|c|c|}
\hline \multicolumn{2}{|c|}{ Kaiser-Meyer-Olkin Measure of Sampling Adequacy. } & .853 \\
\hline Bartlett's Test of Sphericity & Approx. Chi-Square & $1.429 \mathrm{E} 3$ \\
\hline & $\mathrm{df}$ & 300 \\
\hline & Sig. & .000 \\
\hline
\end{tabular}


Overall KMO value coefficient of the variable is 0.853 from Table 2, indicating that the questionnaire validity is high, and the significant factor level sig $=0.000$, less than 0.05 significant level. Therefore, rejecting the null hypothesis, variables have relationship, which is suitable for factor analysis.

Descriptive Statistical Analysis. According to the sample data analysis, overall satisfaction on teaching education between the upper level, which are shown in Table 3, showing that the graduates satisfaction is higher and the other five variables mean all over satisfaction level.

Table 3 Mean standard deviation of population variables

\begin{tabular}{|c|c|c|c|}
\hline variable & item & mean & Standard deviation \\
\hline Professional ethics & 3 & 4.4368 & .15939 \\
\hline Professional knowledge capacity & 8 & 4.3838 & .25377 \\
\hline Practical ability & 3 & 3.9300 & .26627 \\
\hline Comprehensive quality cultivation & 4 & 4.1225 & .16998 \\
\hline Management and service & 6 & 4.0940 & .34696 \\
\hline Education teaching job satisfaction & 1 & 4.4000 &. \\
\hline
\end{tabular}

Factor Analysis. Table 4 shows the result of the common degree of each variable. It can be concluded from this table that the variables common degree of factor analysis are very high, indicating that most information in the variable can be extracted by the factor, and the result of factor analysis is effective.

Table 4 Common degree of variables

\begin{tabular}{|c|c|c|c|c|c|c|c|c|c|c|c|c|c|c|c|c|c|c|c|c|c|c|c|c|}
\hline A & A & A & B & B & B & B & B & B & B & B & C & C & C & D & D & D & D & E & E & E & E & E & E & F \\
1 & 2 & 3 & 1 & 2 & 3 & 4 & 5 & 6 & 7 & 8 & 1 & 2 & 3 & 1 & 2 & 3 & 4 & 1 & 2 & 3 & 4 & 5 & 6 & \\
\hline 0 & 0 & 0 & 0 & 0 & 0 & 0 & 0 & 0 & 0 & 0 & 0 & 0 & 0 & 0 & 0 & 0 & 0 & 0 & 0 & 0 & 0 & 0 & 0 & 0 \\
. &. &. &. &. &. &. &. &. &. &. &. &. &. &. &. &. &. &. &. &. &. &. &. &. \\
5 & 6 & 5 & 5 & 6 & 7 & 6 & 6 & 6 & 7 & 7 & 7 & 6 & 5 & 6 & 6 & 4 & 6 & 6 & 7 & 6 & 6 & 6 & 6 & 6 \\
7 & 5 & 6 & 9 & 0 & 6 & 2 & 5 & 2 & 0 & 5 & 1 & 9 & 5 & 6 & 8 & 5 & & 5 & 1 & 7 & 9 & 8 & 8 & 2 \\
1 & & 9 & 9 & 5 & & 6 & 1 & 7 & 9 & 4 & 7 & 8 & 7 & 6 & 7 & 6 & & 5 & 4 & 6 & 9 & 7 & 3 & 7 \\
\hline
\end{tabular}

Table 5 shows the results of factor contribution rate, of which only characteristic value of the first factor is greater than 1 , and occupying $70.151 \%$ of the total eigenvalue. Therefore, the first factor is extracted as the main factor.

Table 5 factor contribution rate

\begin{tabular}{|c|c|c|c|c|c|c|}
\hline Component & \multicolumn{3}{|c|}{ Initial Eigenvalues } & \multicolumn{3}{c|}{ Extraction Sums of Squared Loadings } \\
\hline & Total & $\begin{array}{c}\text { \% of } \\
\text { Variance }\end{array}$ & Cumulative \% & Total & $\begin{array}{c}\text { \% of } \\
\text { Variance }\end{array}$ & Cumulative \% \\
\hline 1 & 3.508 & 70.151 & 70.151 & 3.508 & 70.151 & 70.151 \\
\hline 2 & .509 & 10.171 & 80.322 & & & \\
\hline 3 & .420 & 8.408 & 88.731 & & & \\
\hline 4 & .309 & 6.171 & 94.901 & & & \\
\hline 5 & .255 & 5.099 & 100.000 & & & \\
\hline
\end{tabular}

Through factor rotation, each factor has a clear meaning, and the correlation between the factor and five variables is strong. Therefore, the education and teaching work evaluation is evaluated by five independent variables. 
Table 6 factor loading value after rotation

\begin{tabular}{|c|c|c|c|c|c|}
\hline Component & A & B & C & D & E \\
\hline 1 & 0.761 & 0.868 & 0.837 & 0.886 & 0.831 \\
\hline
\end{tabular}

Table 7 Variance analysis table

\begin{tabular}{|c|c|c|c|c|c|c|}
\hline \multicolumn{2}{|c|}{ Model } & Sum of Squares & df & Mean Square & F & Sig. \\
\hline 1 & Regression & 36.152 & 5 & 7.230 & 15.061 & $.000^{\text {a }}$ \\
\hline & Residual & 50.407 & 105 & .480 & & \\
\hline & Total & 86.559 & 110 & & & \\
\hline
\end{tabular}

Regression Analysis. The results of variance analysis is presented in table 7, $\mathrm{F}$ value is 15.061 and corresponding $\mathrm{p}$ value is 0.000 , which is less than 0.05 significant level. Consequently, explain part of five independent variables is very significant.

Table 8 Significance test of regression coefficient

\begin{tabular}{|c|c|c|c|c|c|c|}
\hline \multirow{2}{*}{\multicolumn{2}{|c|}{ Model }} & \multicolumn{2}{|c|}{$\begin{array}{l}\text { Unstandardized } \\
\text { Coefficients }\end{array}$} & \multirow{2}{*}{$\begin{array}{c}\text { Standardized } \\
\text { Coefficients } \\
\text { Beta } \\
\end{array}$} & \multirow[b]{2}{*}{$\mathrm{t}$} & \multirow[b]{2}{*}{ Sig. } \\
\hline & & B & $\begin{array}{l}\text { Std. } \\
\text { Error }\end{array}$ & & & \\
\hline \multirow[t]{6}{*}{1} & (Constant) & .740 & .698 & & 1.060 & .000 \\
\hline & A & .003 & .159 & .002 & .018 & .000 \\
\hline & $\mathrm{B}$ & .253 & .220 & .138 & 1.151 & .000 \\
\hline & $\mathrm{C}$ & .072 & .112 & .073 & .643 & .000 \\
\hline & $\mathrm{D}$ & .083 & .135 & .079 & .619 & .000 \\
\hline & $E$ & .472 & .122 & .433 & 3.875 & .000 \\
\hline
\end{tabular}

Table 8 indicates the regression coefficients and corresponding statistics of linear regression models, in which coefficients of constants and five independent variable were $0.003,0.253,0.072$, 0.083 , 0.472, indicating that education teaching job satisfaction has great relevance with professional knowledge, management and service ability. Meanwhile, applied colleges should focus on improving satisfaction of these two aspects. In addition, the corresponding probability of constant and five variables in the linear regression model is 0.000 , indicating that the system is very significant and consistent with the results of variance analysis in table 7.

\section{Countermeasures of Improving Graduates' Satisfaction of Education and Teaching Work in Logistics Management}

Based on data and the analysis results of satisfaction survey, combining the characteristics and fact of logistics professional in applied colleges, this paper timely diagnoses the problems of education teaching work, Outlines weak links in the process of education teaching to carry out, and finally, putting forward the following several aspects of feasibility measures and suggestions based on investigation and study.

Improve Students' Knowledge Ability Level. Deepen cooperation between colleges and enterprises and open enterprise classroom

Realize that students go out and enterprises come in. College can choose corresponding logistics enterprises to let students understand position requirements of enterprises through summer practice or internship as to eliminate students' strangeness to enterprise. Meanwhile, this way also let students understand the problems of logistics operation process and take these problems back to 
school, then solving practical problems according to course theory study. What's more, colleges can adopt the way of enterprise tutor cultivation, which train students as enterprise staffs according to practical work requirements, and admit students understanding that enterprise employees should have the quality and the basic skills. This mixing teaching way not only can provide practice internship opportunities for students, but also cultivate students' strain capacity to find problems and solve the problem.

Improve Teachers' Professional Level and Ensure Teaching Quality. To innovate teachers and strengthen construction of double teachers, colleges could plan to send full-time teachers to finish field exercise in domestic companies and hire industry experts, experts of logistics business enterprises to implement special instruction. This way aim at further optimizing knowledge structure of teachers, education structure, title structure and learn edge structure, and improving teachers' professional knowledge and social influence.

Establish an Impeccable Satisfaction Management System of Education Teaching. Establishing and perfecting satisfaction management system of education teaching job is a dynamic process, which is not visible in the short term and may take a long time to receive the results, therefore, continuous and dynamic observation or evaluation shall be maintained. Meanwhile the assignment should be tracked and supervised by special department, which is in charge of survey, analysis, inspection, improvement of education teaching job satisfaction. Finally, colleges need regularly organize experts to evaluate job satisfaction evaluation management system of education teaching evaluation, and organize the students to survey education teaching job satisfaction.

Improve Students' Service System. Taking campus life and the needs of all-round development of students' satisfaction as the guidance, colleges should establish and consummate students' service mechanism, caring for students from students' mental, living, learning, growing and development by some activities carrier ,for example, "two to visit to gen", "students' witness activity" and "civilized dormitory creation", to set up and run a perfect service system, finally to improve the students' satisfaction.

\section{Acknowledgements}

The 2014 Year Wuhan Technology and Business University the Second Round Research Project of Doctoral Fund (grant number D2014006) host: Rongyan Zhu

Professional Core Curriculum Construction Project (grant number 2015HX012) host: Rongyan Zhu

\section{References}

[1] J.Guo, Graduates' employment influencing factors of applied colleges, Jiangsu Science and Technology Information, 2014, pp. 28-29.

[2] C.W.Zhang, F,Chen, Graduates' employment market exploration and practice in applied colleges and universities in wuhan city, China Business Theory, 2015, pp. 188-189.

[3] J.L.Yang, Y.Gao, Employment status of college graduates in applied colleges -- quantitative analysis based on employment quality report of 15 universities in shaanxi province in 2014, Modern Education Management, 2016, pp. 120-124. 